\title{
PADRONIZAÇÃO PROJETUAL E CONFORTO TÉRMICO: O CASO DO CONDOMÍNIO CIDADE MADURA, EM CAJAZEIRAS-PB
}

\author{
PROJECTUAL STANDARDIZATION AND THERMAL COMFORT: THE \\ CASE OF MADURA CITY CONDOMINIUM, IN CAJAZEIRAS-PB
}

\author{
Victoria Torres de Menezes Araújo ${ }^{1}$ \\ Emanoella Bella Sarmento Salgueiro Eliziário Matias ${ }^{2}$ \\ Rafael Costa de Carvalho Abrantes ${ }^{3}$ \\ Pollyanna Priscila de Souza Lima ${ }^{4}$ \\ André Ferreira Costa ${ }^{5}$ \\ Melina Cavalcanti de Melo Bichinho ${ }^{6}$
}

RESUMO: OBJETIVO: avaliar a qualidade ambiental do Condomínio Cidade Madura (CCM), localizado na cidade de Cajazeiras-PB, considerando aspectos de conforto térmico. MÉTODO: Trata-se de uma pesquisa exploratória com intuito de aproximar-se do tema e apropriar-se da defesa buscando torná-lo mais evidente e fundamentado. A pesquisa foi realizada com foco na avaliação do conforto térmico na unidade residencial do CCM, na cidade de Cajazeiras-PB. RESULTADOS E DISCUSSÕES Com a mudança de perfil da sociedade, relacionada ao aumento da expectativa de vida, a taxa de idosos tem crescido gradativamente. Em detrimento disso, o governo deparou-se com a emergência de investir em habitações para idosos, garantindo o direito à moradia, inclusão social e atendimento à saúde. Baseado nisso, o Condomínio Cidade Madura foi desenvolvido seguindo esses critérios. Contudo, no que diz respeito à qualidade ambiental, sobretudo térmica, é questionável por ser um projeto padrão, reproduzido em diferentes locais e que possuem condições climáticas distintas, como é o caso das cidades paraibanas, Cajazeiras e João Pessoa. Para a comprovação dessa pressuposição, foram usados como procedimentos metodológicos a análise bibliográfica e em meios eletrônicos, bem como a avaliação do projeto arquitetônico e estudo de campo nos condomínios de ambas as cidades, para o cruzamento de dados, sob o auxílio das normas

\footnotetext{
${ }^{1}$ Graduada em Arquitetura e Urbanismo pela Faculdade Santa Maria, Cajazeiras, Paraíba.

2 Docente da Faculdade Santa Maria, Cajazeiras, Paraíba.

${ }^{3}$ Docente da Faculdade Santa Maria, Cajazeiras, Paraíba.

4 Docente da Faculdade Santa Maria, Cajazeiras, Paraíba.

5 Docente da Faculdade Santa Maria, Cajazeiras, Paraíba.

${ }^{6}$ Docente da Faculdade Santa Maria, Cajazeiras, Paraíba.
} 
brasileiras. Nesse estudo, percebeu-se que é de suma importância a avaliação do clima local antes da execução da edificação. Em relação ao Condomínio Cidade Madura, no decorrer do trabalho, notou-se que algumas alterações foram necessárias devido ao mau desempenho térmico das edificações, contudo as modificações que foram precisas em um local, para outro poderiam ter sido de grande contribuição. CONCLUSÃO: Baseando nisso, concluiu-se que a elaboração e desenvolvimento do projeto, convém enaltecer as particularidades locais, evitando danos e desconforto aos usuários idosos.

Palavras chave: Conforto térmico. Habitação Social. Habitações para idosos. Padronização projetual.

ABSTRACT: The thermal comfort demarcations are highly variable and complex to be defined. The sense of well-being is understood in the relation in which the man is in his habitat, being exempt of heat or cold. Therefore, the thermal comfort depends on variables influenced by wind and humidity phenomena. Considering these factors, in cases of project standardization, most of the time they are disregarded due to the concern with the quantitative, that means, the greater number of reproductions. Housing of social interest has followed a pattern since the 20th century, when residential units are reduced in terms of area $\left(\mathrm{m}^{2}\right)$, for greater quantity and/or reduction of costs. With the changing profile of society related to the increase in life expectancy, the rate of the elderly has grown gradually. In detriment of that, the government was faced with the emergence of investing in housing for the elderly, guaranteeing the right to shelter, social inclusion and health care. Based on this fact, the Cidade Madura condominium was developed following these criteria. However, with respect to environmental quality, especially thermal, it is questionable because it is a standard project, reproduced in different places and with distinct climatic conditions, as is the case in the cities of Cajazeiras and João Pessoa. In order to prove this assumption, bibliographic analysis and electronic means were used as methodological procedures, as well as the evaluation of the architectural design and field study in the condominiums of both cities, to cross-checking data under the aid of Brazilian standards. In this study, it was noticed that the evaluation of the local climate before the execution of the building is of major importance. Regarding the Cidade Madura condominium, during the work, it was noticed that some alterations were necessary due to the bad thermal performance of the buildings, however the modifications that were needed from one place to another could have been of great contribution. On this basis, it was concluded that the elaboration and development of the project, it is worth highlighting the local particularities, avoiding damages and discomfort to the elderly users.

Keywords: Thermal comfort. Social habitation. Housing for the elderly. Design standardization. 


\section{INTRODUÇÃO}

A arquitetura bioclimática é conceituada de acordo com Neves (2006) com diversos requisitos que contribuem para a otimização dos impactos ao meio ambiente, bem como a conservação de energia e conforto ambiental no espaço construído. No que diz respeito ao bioclimatismo são aproveitados e levados em conta para a elaboração de projetos, os recursos oferecidos pela natureza, como o aproveitamento do sol, do vento e a utilização de materiais regionais que amenizem os conflitos ambientais, causados, principalmente, pela construção civil.

Efetivamente, como apresenta o autor, deve ser enaltecida a importância de projetos elaborados de forma estratégica, fazendo uso de elementos naturais como complementos, garantindo assim, o conforto ambiental por meio de condicionamentos passivos, ou seja, de forma que não cause tanto impacto no meio ambiente.

Embora a arquitetura bioclimática seja uma realidade cada vez mais próxima e eficiente, existem lacunas questionáveis na implantação desta, em projetos padronizados que, possivelmente, tornar-se-iam ineficientes devido à falta de estudos na implantação do projeto. Isso decorre do fato de serem planejados para uma localidade e executados em outra, com características bioclimáticas diferentes, a exemplo das direções do vento, da umidade relativa do ar e do nível de pluviosidade. Parece relevante, então, considerar esse aspecto de conforto ambiental, sobretudo térmico, em todos os espaços, em especial residenciais, considerando ser esse um local de abrigo maior para o homem.

Em relação às habitações sociais é comum identificar como problemática, questões de conforto, tendo em vista que há sempre uma padronização projetual deixando a mercê, a qualidade do ambiente já que a preocupação com a quantidade de unidades é superior às melhorias do espaço.

No que compete ao presente estudo, é válido ressaltar sobre a elaboração e construção de Habitações de Interesses Sociais (HIS) no Brasil que, segundo 
Galvão, Ornstein e Ono (2013), intensificou-se a partir da segunda metade do século XX com a necessidade de retirar das ruas, pessoas que não tinham como pagar por moradias. Com isso, as HIS passaram a ser projetadas de modo que otimizassem o tempo e o custo, com o intuito de abrigar estas pessoas. Com base nestes autores, os projetos das moradias sociais eram realizados de forma que os projetistas supunham quais eram as necessidades dos usuários fazendo com que as habitações se tornassem utópicas. As questões ergonômicas e espaciais passaram a ser conceituadas a partir de um modelo padrão humano e replicado a outros projetos. Além disso, a repetição na plástica e arquitetura tornaram-se constantes acarretando no desconforto e falta de humanização do espaço.

Partindo da ideia dos exemplos de HIS no Brasil, o governo estadual da Paraíba desenvolveu um projeto conhecido como Condomínio Cidade Madura (CCM), idealizado e executado pela Secretaria Estadual dos Direitos Humanos (SEDH) juntamente com a Companhia Estadual de Habitação Popular (CEHAP) que, trata-se de uma habitação social com objetivo de abrigar idosos autônomos, ou seja, capazes de realizar as atividades domésticas.

O projeto foi desenvolvido nas cidades paraibanas, tendo iniciado em junho de 2014 na cidade de João Pessoa e construído sucessivamente em Campina Grande, em maio de 2015, Cajazeiras, em março de 2016, Guarabira, em maio de 2017, e recentemente em Sousa, em março de 2018.

Ao considerar o que foi dito, surge o questionamento acerca da reprodução de edificações em localidades distintas e condições bioclimáticas tão diversas: É salutar a configuração padronizada das habitações sociais em lugares diferentes, considerando a qualidade ambiental, sobretudo o conforto térmico?

Cada lugar resguarda particularidades ao tratar do conforto térmico. São consideradas características como temperatura, pluviosidade, vento e umidade, fatores que interferem na qualidade do ambiente. Nesse sentido, cada projeto deve ser elaborado de forma a considerar os elementos citados, assim como o local de implantação, evitando desordens e desconforto.

As variantes das condições climáticas de um lugar para outro são muitas e cada localidade tem características distintas que devem ser avaliadas antes da iniciação de qualquer projeto. Assim, a reprodução de projetos pode ser efetuada de 
maneira errônea devido à ausência de atenção para requisitos que favorecem o conforto ambiental, sobretudo térmico, nas edificações.

Pelo exposto, apesar de ser um projeto funcional em termos de garantia de moradia, sabe-se que, em relação ao conforto térmico e condições espaciais, cada usuário apresenta necessidades e limitações diferentes, bem como, o local de implantação demonstra condições climáticas distintas que podem interferir na qualidade do projeto.

É de suma importância esclarecer, portanto, que o programa de habitação CCM foi projetado para a cidade de João Pessoa, considerando o clima local. Contudo, o projeto foi reproduzido nas demais cidades paraibanas tornando-se projeto padrão.

Com base nessas informações e, considerando as divergências do clima, emergiu a necessidade de avaliar o CCM da cidade de Cajazeiras-PB, considerando a avaliação de esquadrias, implantação no terreno, bem como a existência de vegetação ou a ausência da mesma. O conceito de conforto térmico é variável de acordo com o lugar que será realizado o projeto e as características bioclimáticas definem o que pode ser considerado ideal para o clima seco ou úmido (FROTA; SCHIFFER, 2003).

A propósito destas afirmações, é de suma importância avaliar o CCM com localidades distintas em que se destacam, sobretudo, certa disparidade acerca do clima para comprovar a importância da particularidade de cada projeto garantindo a qualidade ambiental. A presente pesquisa traz como característica principal uma Avaliação Pós Ocupação (APO), objetivando identificar as problemáticas existentes que interferem na qualidade de moradia do CCM.

Neste sentido, a presente pesquisa tem como objetivo, avaliar a qualidade ambiental do Condomínio Cidade Madura (CCM), localizado na cidade de Cajazeiras-PB, considerando aspectos de conforto térmico. 


\section{MÉTODO}

Trata-se de uma pesquisa exploratória com intuito de aproximar-se do tema e apropriar-se da defesa buscando torná-lo mais evidente e fundamentado.

A pesquisa foi realizada com foco na avaliação do conforto térmico na unidade residencial do CCM, na cidade de Cajazeiras-PB.

A pesquisa foi norteada a partir de normas e diretrizes que obedecem a Resolução 466/12, publicado dia 13 de junho de 2013 na edição № 112 do Diário Oficial da União (DOU), a qual incorpora os referenciais básicos da bioética, bem como os princípios éticos da autonomia, não maleficência, beneficência e justiça.

Foi garantido todo o esclarecimento necessário, conforme o Termo de Compromisso e Responsabilidade dos Pesquisadores - Responsável e Participante (s), bem como, absoluto sigilo das informações individualizadas obtidas durante todas as etapas. O responsável pela residência assinou o Termo de Consentimento Livre Esclarecido (TCLE), constando as principais informações referentes à pesquisa.

\section{RESULTADO E DISCUSSÕES}

Verificou-se com os resultados, que o Condomínio Cidade Madura, por se tratar de uma Habitação de Interesse Social (HIS) voltada especificamente para idosos e reproduzido de maneira padronizada, mantém ainda seu projeto arquitetônico inalterado. Contudo, existem características que diferem sua construção de uma cidade para outra, a exemplo da implantação no terreno, na qual são adaptadas as distribuições das unidades residenciais de acordo com a locação. 
Como já esclarecido, a pesquisa teve como objetivo avaliar as condições de qualidade ambiental, principalmente térmicas, na reprodução deste projeto governamental de Habitação Social em cidades com climas distintos.

No que diz respeito ao presente projeto de pesquisa, as observações foram feitas por meio de visitas exploratórias nos CCM de João Pessoa e Cajazeiras, ambas cidades paraibanas. Vale ressaltar, que o objeto de estudo é o condomínio de Cajazeiras por ser o terceiro projeto realizado no estado, como também por estar localizado em um local com clima caracterizado quente-seco, o que difere das condições climáticas de onde foi construído o primeiro condomínio, na cidade de João Pessoa, onde é predominantemente quente-úmido, por essa razão será usado como interface projetual para avaliação da qualidade ambiental.

Sob tal enfoque, a pesquisa avalia as condições térmicas da unidade habitacional por meio de elementos arquitetônicos que não interfiram na estrutura da residência, tendo em vista que essa é uma das exigências feitas pelo programa organizacional do projeto habitacional. É intencional que a formação da ideia apresente propostas que possam ser acrescentadas contribuindo com o conforto térmico, bem como servir de modelo para melhoria de projetos futuros.

Nesse sentido, a análise foi direcionada por meio das normas de desempenho do CAU NBR 15575 (ABNT, 2013), em que aborda os critérios básicos que devem ser seguidos para que a edificação possa ser habitada considerando a qualidade do ambiente, dando prioridade ao usuário e suas necessidades básicas, assim como o papel do Arquiteto e Urbanista como principal responsável em ofertar todas as condições impostas. Além disso, a NBR 15220 (ABNT, 2004), que aborda sobre o desempenho térmico das edificações, estabelecendo instruções para o aproveitamento da iluminação e ventilação natural de acordo com a zona climática e estação a qual se refere a cidade em estudo.

Compreende-se assim, que a contribuição para a identificação da habitabilidade e do melhor desempenho térmico da unidade residencial é de suma importância para a garantia da qualidade de vida dos idosos nesses espaços, realçando as disparidades de clima e temperatura das cidades de João Pessoa e Cajazeiras. 


\section{Avaliação Climática}

Pelo exposto, constatou-se que a padronização projetual ocorre com o intuito de minimizar custos na elaboração de projetos, mas é inegável que cada lugar possui suas particularidades que devem ser previstas para o melhor custo/benefício na execução, assim como para o usuário.

O Instituto Nacional de Meteorologia (INMET) fornece dados relacionados ao clima e temperatura de cada estado, bem como previsões de tempo, porém há uma limitação em relação à quantidade de municípios os quais são avaliadas essas estações, como foi o caso de Cajazeiras, em detrimento disso foram usados dados da cidade de São Gonçalo-PB, localizado a 32,3 km.

Com efeito, para comprovação e avaliação das diferentes condições climáticas das cidades paraibanas, João Pessoa e Cajazeiras, foi feita uma comparação entre as temperaturas no período mais quente do ano.

$\mathrm{Na}$ cidade de João Pessoa, no mês de fevereiro a temperatura pode chegar a $30,5^{\circ} \mathrm{C}$ de acordo com as informações disponibilizadas pelo INMET (2019) entre os anos de 1961 a 2009. Em contrapartida, os meses de outubro e novembro apresentaram $34,8^{\circ} \mathrm{C}$ e logo em seguida há uma queda mínima.

A propósito desses informes, é inegavelmente perceptível que as condições de temperatura são adversas, mesmo considerando que os dados representam o pior cenário da temperatura em ambas as cidades, com disparidade de $4,3^{\circ} \mathrm{C}$.

Ademais, foi feita também uma relação entre os meses considerados mais frios do ano baseado no INMET (2019) durante os anos de 1961 a 2009.

Então, nota-se que o trimestre mais frio do ano tendo uma queda durante os meses, sendo o mês de agosto o mais frio. Ao analisar a tendência da queda de temperatura é a mesma, podendo chegar a $19^{\circ} \mathrm{C}$ no mês de julho. Apesar de ser notado a divergência na temperatura da cidade de João Pessoa para a de São Gonçalo, existem outros fatores que podem interferir na sensação térmica, como a umidade do ar referente a quantidade de moléculas d'água que contribui com o 
resfriamento, vento, que de certa forma, tende a ser um dos fatores mais importantes para a contribuição térmica objetivando deixar o ambiente interno mais refrescante do que o externo e quantidade de céu aberto, pois as nuvens impendem a incidência direta dos raios solares, quando há a presença de nuvens, os raios solares são difundidos.

Além disso, a pluviosidade pode ser um fator importante a ser considerado, pois o nível de água no solo pode interferir no aquecimento da terra sendo diretamente ligado a transferência de calor. Silva e Rodal (2019) alegam que quanto maior o índice e período pluviométrico, maiores são as condições se manter a vegetação, que também é um contribuinte para produção de microclima.

Os meses de maio, junho e julho são os meses com maiores níveis pluviométricos, sendo que em junho essa condição tem um acúmulo de $340 \mathrm{~mm}$, mês mais chuvoso, também por se tratar de uma capital litorânea.

O segundo dado de pluviosidade tem uma queda considerada em São Gonçalo, sendo fevereiro, março e abril o período que mais chove no ano de modo que o mês de março tem o nível pluviométrico de $248 \mathrm{~mm}$.

É inegável que há uma grande diferença no índice de chuva de João Pessoa para São Gonçalo, sendo outro fator contribuinte para as condições climáticas de ambas as cidades.

Essa disparidade aparece no trimestre mais seco do ano. Em João Pessoa, têm-se uma estimativa de $102 \mathrm{~mm}$ de nível pluviométrico durante os meses de outubro, novembro e dezembro. No entanto, esse índice cai consideravelmente em São Gonçalo, referente a Cajazeiras, em que os meses de setembro, outubro e novembro são os mais seco do ano e a sensação térmica é elevada devido à baixa umidade do ar.

Além disso, conforme a NBR 15220-2 (ABNT, 2004), o Brasil é dividido em oito zonas climáticas, baseado no clima de cada localidade. A partir da identificação da zona que está localizada a cidade em estudo, é possível avaliar diretrizes pela norma brasileira relacionadas a dimensionamento de aberturas para ventilação, proteção que deve ser usada nas aberturas, entre outros. 
Então, considerando o que foi exposto, ao analisar as divisões das zonas bioclimáticas brasileiras, identificou-se que a cidade de Cajazeiras, PB está localizada na zona 7 e João Pessoa, PB situa-se na zona 8.

\section{Diagnóstico da Unidade Residencial}

\section{Aberturas}

Em geral, as esquadrias e outros elementos são adotados em uma edificação com intuito de aproveitamento de ventilação e luz natural, contudo para o uso adequado desses meios deves ser levado em consideração o local de implantação, as condições climáticas e qual a melhor forma de locar as aberturas para o aproveitamento desses fenômenos.

Para isso, a NBR 15220-2 (ABNT, 2004) onde são apresentadas as zonas bioclimáticas brasileiras, também são dadas diretrizes que auxiliam na adequação do projeto dependendo da zona de localização da cidade em estudo. Ao que se refere a cidade de Cajazeiras, PB, foi analisado o mapa das zonas e identificou-se que sua localização.

Em relação à zona bioclimática 7 , é indicado pela norma brasileira que, as aberturas para a ventilação sejam pequenas devido a característica do clima ser predominantemente quente, ou seja, ao consentir que haja uma ventilação cruzada durante o dia, permite que a temperatura no interior da edificação se aproxime à temperatura externa, outrossim, indica-se que todas as aberturas sejam sombreadas.

Acrescenta-se ainda que, as vedações externas e a coberta dessas edificações sejam pesadas, pois isso favorece para refrear a condução da temperatura para o interior da residência, além disso, a norma aborda sobre estratégias de condicionamento térmico passivo, relacionadas às zonas das cartas correspondentes as estratégias estabelecidas. 
Da mesma forma, foi feita a avaliação de João Pessoa, PB, em relação ao mapa com as divisões das zonas bioclimáticas brasileiras (ABNT, 2004), foi identificado que a cidade está situada na zona 8. De súbito, nota-se uma diferencia gritante entre as duas cidades em questão, as diretrizes para aproveitamento da ventilação natural são distintas, bem como as estratégias de condicionamento térmico, isso se dá devido ao clima predominante de João Pessoa, sendo ele característico quente-úmido, além do favorecimento à circulação do vento e por ser uma cidade litorâneo.

Para as edificações situadas na zona 8 ou seja, João pessoa, diferentemente da zona 7, as aberturas para a ventilação devem ser mais aproveitadas devido ao clima favorável, sendo indicado pela norma brasileira optar por grandes aberturas, mas da mesma forma que indicado anteriormente, também é aconselhado que as aberturas sejam sombreadas.

Ademais, a norma brasileira indica que as vedações externas e as cobertas sejam leves refletoras, ou seja, as alvenarias não precisam ser espeças para impedir a emissão de calor, pois o clima é mais ameno e indica-se ser refletoras para que não absorvam a incidência dos raios solares evitando o aquecimento no interior da edificação. Quanto as estratégias de condicionamento térmico passivo.

Cabe, então, fazer uma ressalva de grande importância no momento de elaboração de projetos, que é considerar a direção do vento, com base no INMET (2019) que é a ventilação, em relação às cidades de João Pessoa e Cajazeiras é predominantemente sudeste, tendo uma variação em sua direção para nordeste em ambas.

Nas unidades residenciais do Condomínio Cidade Madura, conforme as especificações técnicas (2014), a companhia organizacional optou pela utilização de esquadrias em madeira regionais, sendo duas folhas do tipo persiana, modelo padrão para a resedencia de todos os CCM's, assim como o dimensionamento. Essa configuração de janela se repete na sala de estar/jantar, no quarto e na cozinha.

Para a porta de acesso a unidade residencial, também é usada uma folha de madeira regional, conforme o dimensionamento no projeto arquitetônico sendo o modelo padronizado pela Cehap. Nas residências do CCM de Cajazeiras e João 
Pessoa, só possuem uma única porta para entrada e saída da edificação, estando ausente a porta que dá acesso aos fundos.

Sabe-se que para o aproveitamento da ventilação e luz natural, além das janelas e portas, a utilização de cobogós também são alternativas viáveis nas edificações. É possível observar nas imagens seguintes que no projeto pioneiro (CCM de João Pessoa-PB) colocaram no projeto arquitetônico cobogós com o intuito de aproveitar a ventilação, contudo, após a execução do projeto percebeu-se que em períodos chuvosos a água entrava no interior da residência através dessas aberturas, visto isso, na execução dos projetos posteriores, incluindo o CCM de Cajazeiras, foi retirado o elemento, como pode ser observado na comparação feita entre as unidades residenciais dos dois condomínios.

Em relação aos cobogós executados na residência de João Pessoa-PB, alguns moradores interviram, com o objetivo de impedir que a água da chuva entre na edificação colocando cimento nas lacunas.

Devido à interferência do fator natural, a inserção desse elemento de abertura foi interrompida nos projetos posteriores, pois não foi considerado as condições climáticas de outras cidades em que foi realizado o programa de habitação para idosos.

\section{Materiais construtivos}

Sabe-se que todos os fatores que compõem uma edificação sofrem interferências térmicas. Logo, é inegável que os materiais de um edifício e os seus métodos construtivos influenciam nas condições de conforto térmico.

No que concerne as alvenarias, sendo elas externas ou internas, desempenham a função de vedação e/ou divisão entre ambientes. Referente as alvenarias externas, exercem o papel de bloqueio de diversos agentes complexos provenientes do entorno (MARINOSK, 2011).

No entanto, ao que se refere a construção da unidade residencial do CCM, optou-se pela utilização de tijolos cerâmicos, baseado nas especificações técnicas 
(2014) disponibilizado pelo Cehap, para as vedações externas e internas da edificação.

Pelo exposto foi utilizado na edificação o tijolo cerâmico de oito furos, material comum na construção civil brasileira com 90\% das vendas (MARINOSK, 2001), sendo válido destacar que existe uma grande diversidade de tijolos ou blocos de vedação ou autoportantes.

No caso da unidade residencial do CCM, optou-se pela organização das fiadas de tijolos cerâmicos de $1 / 2$ vez. Com efeito, esse material possui vantagens que podem somar ao estudo em questão, por ser leve e também um bom isolante termoacústico.

Em pesquisa realizada pela Quantis Consulting relacionada ao desempenho do material cerâmico, a empresa Construir Mais (2018) divulgou a constatação que, optar pelo uso deste elemento contribui com a sustentabilidade ambiental. Com base nessa análise, o tijolo cerâmico consome $65 \%$ menos de água, além de $83 \%$ a menos de emissão de gases durante o processo construtivo, fator que qualificou a cerâmica com o selo de certificação sustentável.

Outro aspecto que deve ser considerado na avaliação de conforto térmico é a cobertura que, assim como os materiais de vedação, também apresenta um importante papel na edificação, impedindo com que agentes externos e naturais interfiram no interior do edifício e consequentemente na qualidade ambiental do espaço.

Ademais, para a composição da residência do CCM, optou-se por aderir à configuração de coberta (telha canal em cerâmica vermelha) em duas águas, com inclinação de $20 \%$.

Ao que se refere a este material, Bastos (2003) discute sobre a taxa de absorção de água fixada pela NBR 15310 (ABNT, 2005) em 20\%, sendo o valor máximo permitido, fazendo com que a água acumulada no material se transforme em umidade e enquanto a telha é aquecida evapora para o ambiente tornando o clima mais ameno. Contudo, se a taxa de permeabilidade exceder o indicado pode ser comprometida a estrutura e qualidade do ambiente.

Sabe-se que todos os componentes que constituem uma edificação interferem, de certa forma, na qualidade ambiental. Portanto, os materiais de 
revestimento também são considerados na avaliação de condições térmicas, ponderando o desempenho deste nas condições de uma moradia adequada referente ao local de implantação e variações climáticas.

Sob tal enfoque, para o revestimento do piso externo e interno na unidade residencial do CCM foi usada sobre a laje impermeabilizada a pedra cerâmica esmaltada PEI-5 com dimensões de 0,40×0,40.

$O$ revestimento cerâmico se tornou um dos materiais mais indispensáveis na construção civil. As características mais visadas na utilização é a durabilidade, facilidade na limpeza, proteção dos elementos de vedação, isolamento térmico e acústico, entre outros.

Em relação ao uso da pedra cerâmica, deve ser avaliada a área (externa e interna) e o onde será aplicado o revestimento (parede ou piso) seguindo as indicações da NBR 13818 (ABNT, 1997), pois cada uso tem uma particularidade a ser considerada em relação ao tráfego e/ou resistência aos agentes complexos provenientes do entorno e fenômenos naturais (sol, chuva, vento e umidade).

Ademais, Silva et al. (2015), em seu estudo sobre revestimento cerâmico e suas aplicações, explana sobre a utilização deste material em ambientes externos e internos, evidenciando que em espaços abertos em contato com agentes naturais, é indicado que a pedra cerâmica tenha baixa absorção de água e baixa expansão de umidade. Contudo, durante a especificação dos materiais deve ser considerado o clima do local para aplicação de material mais adequado.

Outro aspecto importante que deve ser abordado, é que a absorção de água está diretamente ligada a porosidade do material cerâmico, assim como outros aspectos que estão relacionados, sendo eles a resistência mecânica, a química, ao gelo, entre outros.

Assim, o grau de absorção interfere em diferentes propriedades como a expansão por umidade e a resistência ao gelo. Deve ser evidenciado, como já dito, que a absorção de água está relacionada a porosidade do material, logo, quanto maior for a porosidade menor a resistência a mecânica.

Efetivamente, nas condições térmicas de uma edificação, além dos materiais abordados, existem outros parâmetros que estão relacionados a qualidade 
ambiental e a condução de temperatura do ambiente a ambiente, são eles difusividade térmica e efusividade térmica.

Como define Kappaun (2012) a difusividade térmica está relacionada a capacidade do material de adaptar a temperatura de seu entorno, não expressando a quantidade de energia acumulada, no entanto a baixa difusidade de um material retardam as variações e temperaturas do meio externo para o interno.

A autora também explana sobre efusividade térmica, expondo que está relacionada a capacidade que um material tem de absorver a temperatura, sendo uma das variáveis mais importantes para a construção, servindo para diminuir as oscilações de temperatura provenientes dos materiais.

Assim, a baixa efusividade faz com que a temperatura do material se aproxime do corpo tendo a sensação de uma superfície mais quente, quando ocorre o contrário (efusividade baixa) a superfície tende a ser mais fria.

As tonalidades das pinturas também interferem no conforto térmico, por meio da absorção e emissão de calor, ou seja, quanto mais escura a superfície, se exposta aos raios solares, a absorção da temperatura tende a ser maior o que transfere do meio externo para o interior da edificação, quanto as superfícies mais claras tendem a difundir os raios solares, isto é, parte da radiação é refletida fazendo com que tenha baixa absorção do calor e o ambiente se torne mais ameno.

Nas especificações técnicas (2014) da residência do CCM que descreve sobre os materiais e métodos de construção aborda que, em relação à pintura da unidade residencial deve ser consultada a Cehap sobre as tonalidades e os tipos de tintas utilizadas. Percebe-se que a companhia organizacional optou pelo uso de tonalidades mais suaves, como observado nas figuras a seguir das unidades residências do CCM de Cajazeiras e João Pessoa, respectivamente.

\section{Vegetação}

A radiação solar pode causar muitas oscilações na temperatura dos centros urbanos influenciados por fatores como, verticalização, asfalto e trânsito de carros, 
ocasionando o superaquecimento superficial do solo, provocando as ilhas de calor $^{13}$. Efetivamente, em detrimento desses fatores, quanto maior o calor maior são as modificações nos fenômenos naturais, a exemplo da alteração na circulação dos ventos, da umidade e no nível de pluviosidade (PAULA, 2004).

A vegetação pode ser um importante contribuinte para o conforto térmico de uma edificação ou centros urbanos, pois as plantas têm um grande papel na Terra, que é o de prover oxigênio $(\mathrm{O} 2)$, principal gás responsável pela respiração de grande parte dos seres vivos, além de servir de bloqueio para os raios solares (BRASIL ESCOLA, 2019).

Para a biologia, a fotossíntese tem o significado de "síntese utilizando a luz", esse processo se dá por meio dos raios solares que são transformadas em reações químicas, podendo ocorrer por meio de reações luminosas e de fixação de carbono (BRASIL ESCOLA, 2019).

No que concerne ao estudo sobre a vegetação, o autor Rivero (1986 apud PAULA, 2004) explana que a vegetação pode absorver em até $90 \%$ da radiação solar e $60 \%$ da infravermelha, em que o restante é transmitido entre as folhas ou refletido.

Em conformidade do que já foi visto, além disparidade das condições climáticas entra as cidades de João Pessoa e Cajazeiras, algumas das alterações projetuais prejudicam a qualidade ambiental, sobretudo térmica da unidade residencial, a exemplo da substituição do paisagismo por brita, como acontece no CCM de Cajazeiras.

Após visualizar as imagens comparativas, percebe-se uma grande disparidade, e o que mais chama atenção no decorrer da pesquisa é que a cidade de Cajazeiras é consideravelmente mais quente do que João Pessoa. Para tanto, o paisagismo deveria ser mais favorecido no local em que a umidade do ar e a temperatura deixam a desejar, bem como a necessidade de gerar um microclima para amenizar a temperatura no interior da unidade residencial do CCM de Cajazeiras. 


\section{CONCLUSÃO}

Para maior efeito, a escolha dos materiais que compõem a edificação é indispensável, pois, em sua maioria, funcionam como método para refrear o aquecimento no interior da unidade residencial, outros métodos também avaliados e que contribuem com a amenização do clima é a valorização da vegetação, principal gerador de microclima devido a evaporação das moléculas de água presente nas folhagens.

No que diz respeito à reprodução projetual, em que o principal objetivo é a redução de custos, tende a ser realizada de maneira errônea, principalmente se esse sistema de padronização for disseminado em cidades com uma grande disparidade climática, como o caso estudado.

O Condomínio Cidade Madura foi projetado para uma cidade em que o clima predominante é quente-úmida, o nível de pluviosidade é sempre mais favorável do que em Cajazeiras, além de ter uma grande quantidade de vegetação rodeando a cidade.

Pelo exposto, viu-se que a condição de conforto térmico na unidade residencial do CCM da cidade de Cajazeiras é problemática, pois o nível pluviométrico é bastante baixo, e durante o ano a temperatura é predominantemente elevada, além disso, deve-se considerar que não existem bacias hidrográfica ou rios nas proximidades, tendo a seca como uma realidade frequente. Em suma, como apresenta 0 projeto de pesquisa, existem alternativas que corroboram com a minimização da temperatura no interior da edificação em relação à temperatura externa podendo, então, ser um fator para melhoria do usuário, entre outros aspectos, as alternativas explanadas podem ser acrescidas sem intervir na estrutura da unidade residencial, ou seja, além de servir como proposta para projetos futuros, podem também ser utilizadas nos projetos já existentes como forma de intervenção. 


\section{REFERÊNCIAS BIBLIOGRÁFICAS}

ARAÚJO, Victória Torres de Menezes et al. Análise Espacial das Residências do Condomínio Cidade Madura em Cajazeiras, PB. In: SAUFIP, 5., 2018, Patos, Pb. Anais... Patos, PB: Fip, 2018. p. 1 - 14.

ASSOCIAÇÃO BRASILEIRA DE NORMAS TÉCNICAS. NBR 13817: placas cerâmicas para revestimento - classificação. Rio de Janeiro: ABNT7, 1997. 3 p.

NBR 13818: placas cerâmicas para revestimento - especificação e métodos de ensaio. Rio de Janeiro, 1997. 78 p.

NBR 15220-2: métodos de cálculo da transmitância térmica, da capacidade térmica, do atraso térmico e do fator solar de elementos e componentes de edificações. Rio de Janeiro, 2003. 23 p.

NBR 15220-3: zoneamento bioclimático brasileiro e diretrizes construtivas para edificações unifamiliares de interesse social. Rio de Janeiro: ABNT, 2004. 23p.

NBR 15310: componentes cerâmicos - telhas - terminologia, requisitos e métodos de ensaio. Rio de Janeiro, 2005. 53 p.

NBR 15575-1: Edificações Habitacionais - Desempenho parte 1: requisitos gerais. Rio de Janeiro: ABNT, 2003. 60 p.

BASTOS, Frederico Assis. Avaliação do Processo de Fabricação de Telhas e Blocos Cerâmicos Visando à Certificação do Produto. 2003. 164 f. Dissertação (Mestrado) - Curso de Engenharia Civil, Programa de Pós-Graduação em Engenharia Civil, Universidade Federal de Santa Catarina - Ufsc, Santa Catarina, 2003. Disponível em:

<https://repositorio.ufsc.br/bitstream/handle/123456789/86480/191985.pdf>. Acesso em: 09 maio 2019.

BATISTA, Juliana Oliveira. A Arquitetura e seu Desempenho Térmico no Contexto do Semi- árido Alagoano: estudos de caso em Santana do Ipanema-AL. 2006. 161 f. Dissertação (Mestrado) - Curso de Programa de Pós-Graduação em Arquitetura e Urbanismo - Pósarq, Centro Tecnológico - Ctc, Universidade Federal de Santa Catarina - Ufsc, Florianópolis, 2006.

BRASIL ESCOLA. Fotossíntese. Disponível em: <https://brasilescola.uol.com.br/biologia/fotossintese.htm>. Acesso em: 13 maio 2019.

BRASIL. Decreto no 33.964, de 29 de outubro de 2012. Brasília, DF. CARMO, C.I.; RAIA JUNIOR, A. A.; NOGUEIRA, A. D. A Teoria das Sintaxe Espacial e suas Aplicações na Área de Circulação e 2012.2 Dransportes. 2 Disponível $<$ http://redpgv.coppe.ufrj.br/index.php/es/produccion/articulos- cientificos/2012-1/724-teoria-dasintaxe-espacial-e-suas-aplicacoes-circulacao-e- transportes-pluris-2012/file>. Acesso em: 06 set. 2018.

CODHAB, Companhia de Desenvolvimento Habitacional do Distrito Federal. Carta de Serviços ao Cidadão. Brasília, Df, 2007. 30 p.

CONSELHO DE ARQUITETURA E URBANISMO (Brasil). Guia para Arquitetos na Aplicação da Norma de Desempenho ABNT NBR 15575. Brasília, 2003. 
CONSTRUIR MAIS. O uso da cerâmica e suas vantagens. 2018. Disponível em: $<$ http://www.construirmais.com/revista/index.php/inovar-e-preciso/365-o-uso-da- ceramica-esuas-vantagens>. Acesso em: 09 maio 2019.

FERREIRA, Walter José; ORNSTEIN, Sheila Walbe; ONO, Rosário. Avaliação Pós- ocupação em Empreendimentos Habitacionais no Brasil: da reabilitação aos novos edifícios. In: VILLA, Simone Barbosa; ORNSTEIN, Sheila Walbe. Qualidade Ambiental na Habitação: avaliação pós-ocupação. São Paulo, Sp: Editora Oficina de Textos, 2013. Cap. 2. p. 37-52.

FROTA, Anésia Barros; SCHIFFER, Sueli Ramos. Manual de Conforto Térmico: arquitetura, urbanismo. 8. ed. São Paulo: Studio Nobel, 2003. 243p.

FUNDO DE POPULAÇÃO DAS NAÇÕES UNIDAS (UNFPA) e HELPAGENCE INTERNECIONAL. Envelhecimento no Século XXI: Celebração e Desafio. 2012. Disponível em: <https://www.unfpa.org/sites/default/files/pub-pdf/Portuguese-Exec- Summary_0.pdf>. Acesso em: 09 nov. 2018.

GONÇALVES, Febo Câmara. O Mercado Imobiliário e a Política Habitacional do Distrito Federal: Estudo de Caso do Programa Morar Bem. 2017. 64 f. Monografia (Especialização) Curso de Programa de Pós-Graduação em Economia - Ppge, Universidade de Brasília, Brasília, Df, 2017.

GONÇALVES, Helder; GRAÇA, João Mariz. Conceitos Bioclimáticos para os Edifícios em Portugal. 2004. Lisboa: Ineti.

GUEDES, Elaine Cristina Nascimento et al. Moradia Digna no Projeto Habitacional Cidade Madura: uma questão de mobilidade e acesso no envelhecimento ativo. In: Congresso Internacional Envelhecimento Humano, 5., 2017, Maceió - AL. Anais Maceió: Cieh, 2017. p. 1 6.

GUIMARÃES, Leonardo E. et al. Acompanhamento das Variações das Temperaturas Superficiais dos Principais Materiais Utilizados em Fachadas. In: Encontro sobre Pesquisa de Materiais de Construções, 2. 2002, Goiânia. Anais Goiás: Ufg, 2002. p. 1 - 13. Disponível

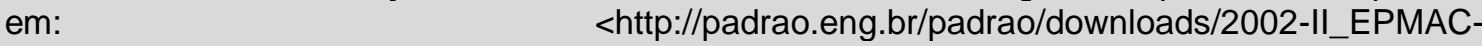
variacoes_de_temperaturas_em_fachadas.pdf>. Acesso em: 20 fev. 2019.

IBGE - Instituto Brasileiro de Geografia e Estatísticas. Projeção da população do Brasil e das Unidades da Federação. 2010.2 Disponível em: <https://www.ibge.gov.br/apps/populacao/projecao/>. Acesso em: 10 nov. 2018.

INMET - Instituto Nacional de Meteorologia. Gráficos Climatológicos. João Pessoa-PB, 1961 1990. Disponível em<http://www.inmet.gov.br/portal/index.php?r=clima/graficosClimaticos $>$. Acesso em: 11 mai. 2019.

São Gonçalo-PB, 1961 - 1990. Disponível em: <http://www.inmet.gov.br/portal/index.php?r=clima/graficosClimaticos>. Acesso em: 11 mai. 2019.

INMET - Instituto Nacional de Meteorologia. Períodos de Maiores e Menores Temperaturas e Pluviosidades Climatológicas. João Pessoa-PB, 1961-2009. Disponível em: <http://www.inmet.gov.br/portal/index.php?r=clima/mesTempo>. Acesso em: 05 abr. 2019.

São Gonçalo-PB, 1961-2009. Disponível em: <http://www.inmet.gov.br/portal/index.php?r=clima/mesTempo>. Acesso em: 05 abr. 2019.

KAPPAUN, Kamila. Avaliação do Desempenho Térmico em Edificações de Blocos Estruturais Cerâmicos e Blocos Estruturais de Concreto para a Zona Bioclimática 2 
Brasileira. 125 f. Dissertação (Mestrado) - Curso de Pós-graduação em Engenharia Civil e Ambiental, Centro Tecnológico, Universidade Federal de Santa Maria, Santa Maria, Rs, 2012.

LAMBERTS, Roberto et al. Desempenho Térmico de Edificações. 3. ed. Florianópolis: Labeee, 2005. 42 p. Disponível em: <http://www.ceap.br/material/MAT25022013164631.pdf>. Acesso em: 24 out. 2018.

LAMBERTS, Roberto; XAVIER, Antônio Augusto de Paula; GOULART, Solange. Conforto e Stresse Térmico. 2008. 108 f. LABEEE (Laboratório de Eficiência Energética em Edificações) Curso de Engenharia Civil, Centro Tecnológico Departamento de Engenharia Civil, Universidade Federal de Santa Catarina, Florionópolis, 2008. Disponível em: $<$ http://www.labeee.ufsc.br/antigo/arquivos/publicacoes/Apconforto.pdf>. Acesso em: 24 set. 2018.

MARINOSK, Davis. Alvenarias: Florianópolis: Labeee, 2011. 32 slides, color. Disponível em: $<$ http://www.labeee.ufsc.br/sites/default/files/disciplinas/Aula\%202-

\%20Alvenarias_\%20introducao\%2Bvedacao.pdf>. Acesso em: 09 maio 2019.

MEDEIROS, Haendel Lopes Virgulino de; MATIAS, Emanoella Bella Sarmento S. E.; COSTA, Angelina Dias Leão. Resgatando a Habitabilidade Local: inserção de rota acessível no centro histórico de João Pessoa - PB. In: ENEAC, 10., 2016, Recife. Anais Recife: Eneac, 2016. p. 1 11. Disponível em: <http://pdf.blucher.com.br.s3-sa-east 1.amazonaws.com/designproceedings/eneac2016/ACE03-4.pdf>. Acesso em: 05 maio 2019.

MELBOOKS (Org.). Melhoramentos Dicionário Língua Portuguesa. São Paulo, Sp: Editora Melhoramentos Ltda, 2011. $326 \mathrm{p}$.

NEVES, Letícia de Oliveira. Arquitetura Bioclimática e a Obra de Severiano Porto: estratégias de ventilação natural.2006. 222 f. Dissertação (Mestrado) - Curso de Arquitetura e Urbanismo, Área de Concentração: Arquitetura, Urbanismo e Tecnologia, Escola de Engenharia de São Carlos da Universidad. 